\title{
Correlation of serum free prostate-specific antigen level with histological findings in patients with prostatic disease
}

\author{
Lakhey $\mathbf{M}^{1}$, Ghimire $\mathbf{R}^{1}$, Shrestha $\mathbf{R}^{2}$, Bhatta $\mathrm{AD}^{3}$
}

${ }^{1}$ Department of Pathology, Kathmandu Medical College Teaching Hospital, ${ }^{2}$ Department of Biochemisty, Tribhuvan University Teaching Hospital, ${ }^{3}$ Department of Urology, Medicare National Hospital and Research Centre

\begin{abstract}
Background: Prostate Specific Antigen (PSA) has been widely used in the diagnosis and management of patients with prostate cancer. It may be elevated in other prostatic diseases and surgical procedures. PSA exists in two forms, a major bound form (cPSA) and a free form (fPSA).

Objectives: The objective of the study was to determine the relationship between serum fPSA levels and histologic findings in biopsy specimens of men with prostatic disease.

Material and methods: This study includes 91 patients planned for transurethral resection of prostate (TURP). Blood samples were collected before TURP and tested for fPSA. Histology of the tissue samples collected after TURP were studied and the relationship with fPSA analysed using SPSS 11.5.

Results: The median values for benign, premalignant and malignant lesions were $1.8 \mathrm{ng} / \mathrm{ml}, 4.5 \mathrm{ng} / \mathrm{ml}$ and $13.20 \mathrm{ng} / \mathrm{ml}$ respectively $(\mathrm{p}<0.001)$. Most cases of benign prostatic hyperplasia $(\mathrm{BPH})$ without inflammation had fPSA levels $<2 \mathrm{ng} /$ $\mathrm{ml}$, while most with active inflammation had levels $>5 \mathrm{ng} / \mathrm{ml}$. Low grade prostatic intraepithelial neoplasia (LGPIN) saw levels $<5 \mathrm{ng} / \mathrm{ml}$ while high grade intraepithelial neoplasia (HGPIN) and prostate cancer (PCa) had levels $>5 \mathrm{ng} / \mathrm{mL}$ $(\mathrm{p}<0.05)$. For detection of high grade lesions (HGPIN and PCa), the sensitivity and specificity of fPSA level $>5 \mathrm{ng} / \mathrm{ml}$ was found to be $88.8 \%$ and $90.2 \%$ respectively.

Conclusions: Serum fPSA is elevated marginally in patients with BPH without inflammation. Active inflammation and high grade lesions are associated with fPSA level more than $5 \mathrm{ng} / \mathrm{ml}$.
\end{abstract}

Key words: Benign prostatic hyperplasia, fPSA, prostate cancer, prostatic intraepithelial neoplasia.

$P^{\prime}$ rostate specific antigen (PSA), a "glycoprotein serine protease", was first identified by Wang et al in $1979^{1}$. It is a widely used serum marker first designed for the early detection and monitoring of patients with prostate cancer $(\mathrm{PCa})^{2-5}$. However it is evident now that a raised PSA level can also occur in non-malignant conditions like benign prostatic hyperplasia (BPH), inflammation, diagnostic and surgical procedures. These conditions may mimic cancer and cause confusion in diagnosis especially in PCa detection programs that use PSA as a screening test. Immunoreactive PSA (total PSA [tPSA]) exists in two forms, a major fraction is bound to serum proteins (cPSA) and about $10-30 \%$ is free (fPSA). There are reports on relationship between serum tPSA levels and histological findings on prostate biopsies. Free PSA measurements can be used to improve the specificity of PSA for PCa, especially when tPSA values are between 4.0 and $10.0 \mathrm{ng} / \mathrm{ml}$. To the best of our knowledge, the relationship between fPSA and histologic findings have not been determined so far. Hence this study was undertaken to investigate the relationship between serum fPSA values and histologic findings in biopsy specimens of men with prostatic disease.

Materials and methods

This study included 91 patients with prostatic disease planned for surgery who attended the urology clinic of Medicare National Hospital and Research Centre from January 2008 to December 2009. Blood samples were taken before transurethral resection of the prostate (TURP), and at least a week after digital rectal examination to avoid possible errors caused by the release of PSA from the prostate. The serum samples were stored at $-20{ }^{\circ} \mathrm{C}$ and were tested for PPSA within 4 days. Free PSA was estimated by sandwich ELISA technique using high affinity Biotin-Streptavidin

Correspondence

Dr. Mamta Lakhey

Associate Professor, Department of Pathology

Kathmandu Medical College Teaching Hospital

E-mail: mlakhey65@yahoo.com 
system, with analytical sensitivity of $0.05 \mathrm{ng} / \mathrm{mL}$ (HUMAN, Germany).

The tissue samples collected after TURP were fixed in $10 \%$ formalin. The tissue was prepared routinely, embedded in paraffin, cut to a thickness of four microns and stained by Hematoxylin- Eosin. The biopsy was studied by a pathologist without the knowledge of the result of serum fPSA value and grouped accordingly.

I. Benign prostatic hyperplasia without and with inflammation, which includes chronic prostatitis, acute prostatitis, chronic active prostatitis.

II. Prostatic intraepithelial neoplasia (PIN), which includes, Low-grade PIN (LGPIN) and High-grade PIN (HGPIN).

III. Prostate Cancer (PCa), which includes, Low-grade PCa (LGPCa) and High-grade PCa (HGPCa).

\section{Statistical analysis}

Data were analysed using the statistical software package SPSS 11.5 for Windows (SPSS). Associations between different diagnostic categories and fPSA were tested with chi square test. Receiver operating characteristic (ROC) curve was generated using SPSS for window. Pvalue $<0.05$ was considered as statistically significant.

Results

This study included 91 males, 47 to 86 years old (mean 67.61 years) diagnosed with benign (BHP with or without inflammation), premalignant (LGPIN and HGPIN) and malignant (adenocarcinoma prostate) lesions of the prostate (Fig 1). The largest number of patients were in the $7^{\text {th }}$ and $8^{\text {th }}$ decade of life.

The patients diagnosed with adenocarcinoma were approximately a decade older than those with benign and premalignant diseases (mean 76.8 vs 67.41 and 64.81 respectively). Most of the patients presented with symptoms of urinary obstruction, frequency of micturition, nocturia and hesitancy.
Out of the 91 patients, $82.41 \%$ cases were benign, while PIN and PCa comprised of $12.08 \%$ and 5.49\% respectively. Most of the benign cases and PIN had fPSA level $<5.0 \mathrm{ng} / \mathrm{mL}$. Four out of five malignant cases had fPSA more than $5.0 \mathrm{ng} / \mathrm{mL}$. The fPSA values for benign, premalignant and malignant lesions ranged from $0.04-19.82 \mathrm{ng} / \mathrm{mL}, 1.20-22.30 \mathrm{ng} / \mathrm{mL}$ and $1.82-$ $35.20 \mathrm{ng} / \mathrm{mL}$ with calculated median value $1.8 \mathrm{ng} / \mathrm{mL}$, $4.5 \mathrm{ng} / \mathrm{mL}$ and $13.20 \mathrm{ng} / \mathrm{mL}$ respectively. The association between different diagnostic groups and fPSA ranges was statistically significant $(\mathrm{p}<0.001$, Table 1$)$.

Of the 75 benign lesions, $65.33 \%$ were BHP without concurrent inflammation, while $28 \%, 2.66 \%$ and $4 \%$ of them showed chronic, chronic active and acute inflammation respectively. Most cases of BHP without inflammation $(46.66 \%)$ had fPSA below $2.0 \mathrm{ng} / \mathrm{mL}$, while most with acute inflammation showed fPSA more than $5.0 \mathrm{ng} / \mathrm{mL}$. The association between the diagnosis and fPSA ranges studied was statistically significant $(\mathrm{p}<0.001$, Table 2).

The premalignant cases comprising LGPIN and HGPIN and malignant cases comprising LGPCa and HGPCa were separately analysed for fPSA levels. The fPSA values of all seven cases of LGPIN were lower than $5.0 \mathrm{ng} / \mathrm{mL}$ while patients of HGPIN and majority of $\mathrm{PCa}$ had values higher than $5.0 \mathrm{ng} / \mathrm{mL}$. The association between different diagnostic groups and fPSA ranges was statistically significant $(\mathrm{p}<0.05$, Table 3$)$.

As most of the benign cases and all LGPIN showed fPSA values significantly lower $(<5.0 \mathrm{ng} / \mathrm{mL})$ than high grade lesions, ROC analysis was done to find an appropriate cut off fPSA value for differentiating HGPIN and PCa from the former (Fig 2). The sensitivity and specificity of $88.8 \%$ and $90.24 \%$ respectively can be achieved using cut off value of $5.0 \mathrm{ng} / \mathrm{mL}$ (Table 4). The association between the two diagnostic groups using this cut off value was statistically significant $(\mathrm{p}<0.001$, Table 5). Odds ratio calculated was 74 (95\%CI: 8.174 to 669.938 ).

Table 1: Major diagnostic categories Vs fPSA level

\begin{tabular}{|l|c|c|c|c|c|c|}
\hline & \multicolumn{7}{|c|}{ PSA Level (ng/mL) } \\
\hline & $\mathbf{0 - 5 . 0}$ & $\mathbf{5 . 0 1} \mathbf{- 1 0 . 0}$ & $\mathbf{1 0 . 0 1 - 1 5 . 0}$ & $\mathbf{1 5 . 0 1 - 2 5 . 0}$ & $>\mathbf{2 5 . 0}$ & Total \\
\hline Benign lesions & $67(73.62 \%)$ & $5(5.49 \%)$ & $1(1.09 \%)$ & $2(2.19 \%)$ & & $75(82.41 \%)$ \\
\hline $\begin{array}{l}\text { Premalignant } \\
\text { lesions }\end{array}$ & $7(7.69 \%)$ & $1(1.09 \%)$ & $1(1.09 \%)$ & $2(2.19 \%)$ & & $11(12.08 \%)$ \\
\hline Malignancy & $1(1.09 \%)$ & $1(1.09 \%)$ & $2(2.19 \%)$ & & $1(1.09 \%)$ & $5(5.49 \%)$ \\
\hline Total & $\mathbf{7 5 ( 8 2 . 4 1 \% )}$ & $\mathbf{7 ( 7 . 6 9 \% )}$ & $\mathbf{4 ( 4 . 3 9 \% )}$ & $\mathbf{4 ( 4 . 3 9 \% )}$ & $\mathbf{1 ( 1 . 0 9 \% )}$ & $\mathbf{9 1 ( 1 0 0 \% )}$ \\
\hline
\end{tabular}


Table 2: Subsets of benign prostatic disease Vs fPSA level

\begin{tabular}{|l|c|c|c|c|c|c|}
\hline & \multicolumn{5}{|c|}{ PSA Level (ng/mL) } & \\
\hline & $\mathbf{0 - 1 . 0}$ & $\mathbf{1 . 0 1 - 2 . 0}$ & $\mathbf{2 . 0 1 - 3 . 0}$ & $\mathbf{3 . 0 1 - 4 . 0}$ & $>\mathbf{5 . 0}$ & Total \\
\hline BPH & $21(28 \%)$ & $14(18.66 \%)$ & $10(13.33 \%)$ & & $4(5.33 \%)$ & $49(65.33 \%)$ \\
\hline BPH with chronic prostatitis & $4(5.33 \%)$ & $8(10.66 \%)$ & $8(10.66 \%)$ & $1(1.33 \%)$ & & $21(28 \%)$ \\
\hline $\begin{array}{l}\text { BPH with chronic active } \\
\text { prostatitis }\end{array}$ & & & $1(1.33 \%)$ & $1(1.33 \%)$ & $2(2.66 \%)$ \\
\hline BPH with acute prostatitis & & & & & $3(4 \%)$ & $3(4 \%)$ \\
\hline Total & $\mathbf{2 5 ( 3 3 . 3 3 \% )}$ & $\mathbf{2 2 ( 2 9 . 3 3 \% )}$ & $\mathbf{1 8}(\mathbf{2 4 \% )}$ & $\mathbf{2 ( 2 . 6 6 \% )}$ & $\mathbf{8 ( 1 0 . 6 6 \% )}$ & $\mathbf{7 5 ( 1 0 0 \% )}$ \\
\hline
\end{tabular}

Table 3: PIN and PCa Vs fPSA level

\begin{tabular}{|l|c|c|c|c|c|c|}
\hline & \multicolumn{5}{|c|}{ PSA Level (ng/mL) } & >25.0 \\
\hline & $\mathbf{0 - 5 . 0}$ & $\mathbf{5 . 0 1 - 1 0 . 0}$ & $\mathbf{1 0 . 0 1 - 1 5 . 0}$ & $\mathbf{1 5 . 0 1 - 2 5 . 0}$ & Total \\
\hline LGPIN & $7(43.75 \%)$ & & & & & $7(43.75 \%)$ \\
\hline HGPIN & & $1(6.25 \%)$ & $1(6.25 \%)$ & $2(12.5 \%)$ & & $4(25 \%)$ \\
\hline LGPCa & & & $1(6.25 \%)$ & & & $1(6.25 \%)$ \\
\hline HGPCa & $1(6.25 \%)$ & $1(6.25 \%)$ & $1(6.25 \%)$ & & $1(6.25 \%)$ & $4(25 \%)$ \\
\hline Total & $\mathbf{8 ( 5 0 \% )}$ & $\mathbf{2 ( 1 2 . 5 \% )}$ & $\mathbf{3 ( 1 8 . 7 5 \% )}$ & $\mathbf{2 ( 1 2 . 5 \% )}$ & $\mathbf{1 ( 6 . 2 5 \% )}$ & $\mathbf{1 6 ( 1 0 0 \% )}$ \\
\hline
\end{tabular}

Table 4: Sensitivity and specificity at different cut off of fPSA to distinguish PCa with other conditions

\begin{tabular}{|c|c|c|}
\hline Cut off & Sensitivity (\%) & Specificity (\%) \\
\hline 1.81 & 100 & 49.0 \\
\hline 4.95 & 80.0 & 86.0 \\
\hline 5.00 & 88.8 & 90.2 \\
\hline 12.65 & 60.0 & 94.0 \\
\hline 13.60 & 40.0 & 95.0 \\
\hline 14.15 & 30.0 & 96.0 \\
\hline 15.45 & 25.0 & 97.0 \\
\hline 21.06 & 20.0 & 99.0 \\
\hline$>28$ & 0 & 100 \\
\hline
\end{tabular}

Table 5: Comparison between low grade lesions (benign and LGPIN) and higher grade lesions (HGPIN and PCa) with cut off fPSA value of $5.0 \mathrm{ng} / \mathrm{mL}$

\begin{tabular}{|l|c|c|c|}
\hline & $\mathbf{0}-\mathbf{5 . 0} \mathbf{n g} / \mathbf{m L}$ & $\mathbf{> 5 . 0} \mathbf{n g} / \mathbf{m L}$ & Total \\
\hline Benign + LGPIN & $74(81.31 \%)$ & $8(8.79 \%)$ & $82(90.10 \%)$ \\
\hline HGPIN + malignant & $1(1.01 \%)$ & $8(8.79 \%)$ & $9(9.90)$ \\
\hline Total & $\mathbf{7 5 ( 8 2 . 4 1 \% )}$ & $\mathbf{1 6}(\mathbf{1 7 . 5 9 \% )}$ & $\mathbf{9 1}(\mathbf{1 0 0 \% )}$ \\
\hline
\end{tabular}




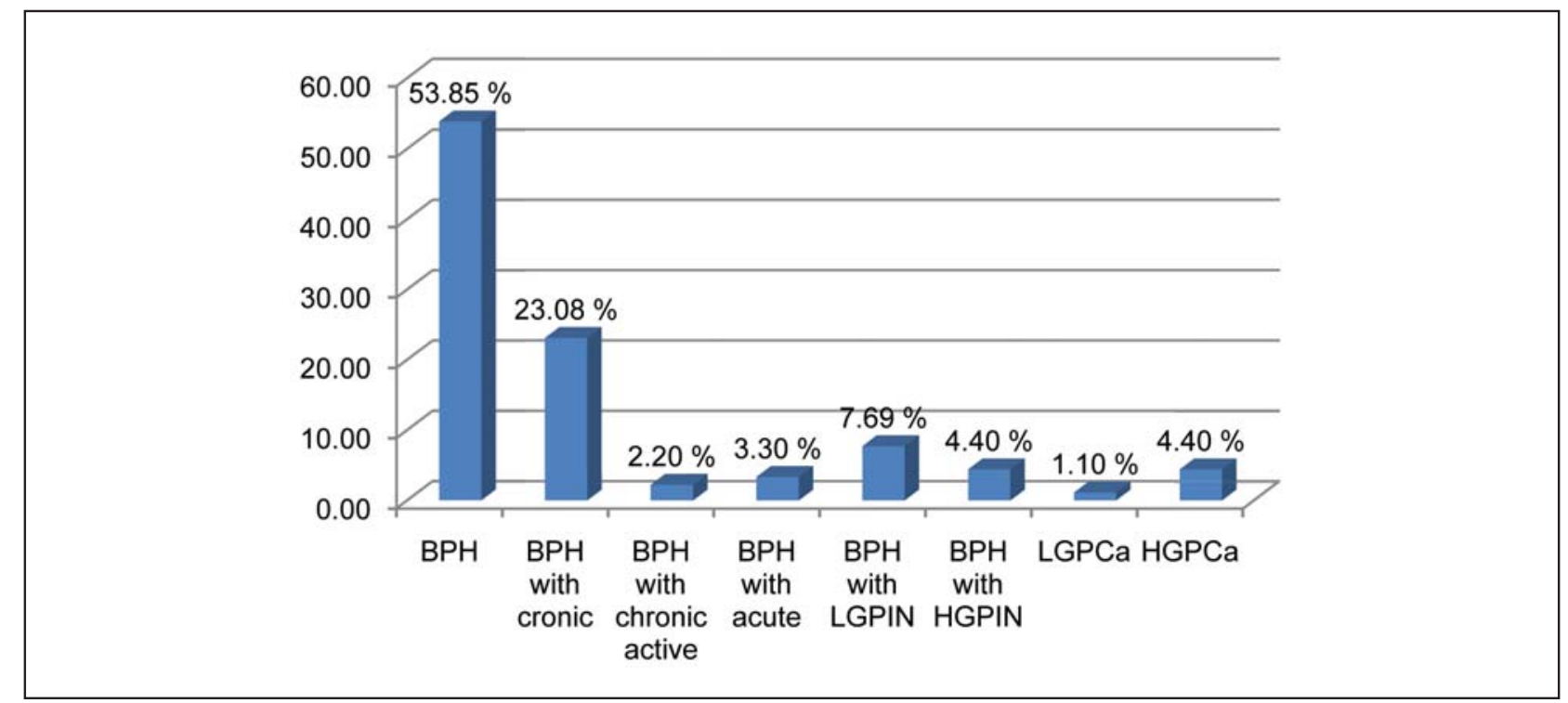

Fig 1: Distribution of prostatic lesions

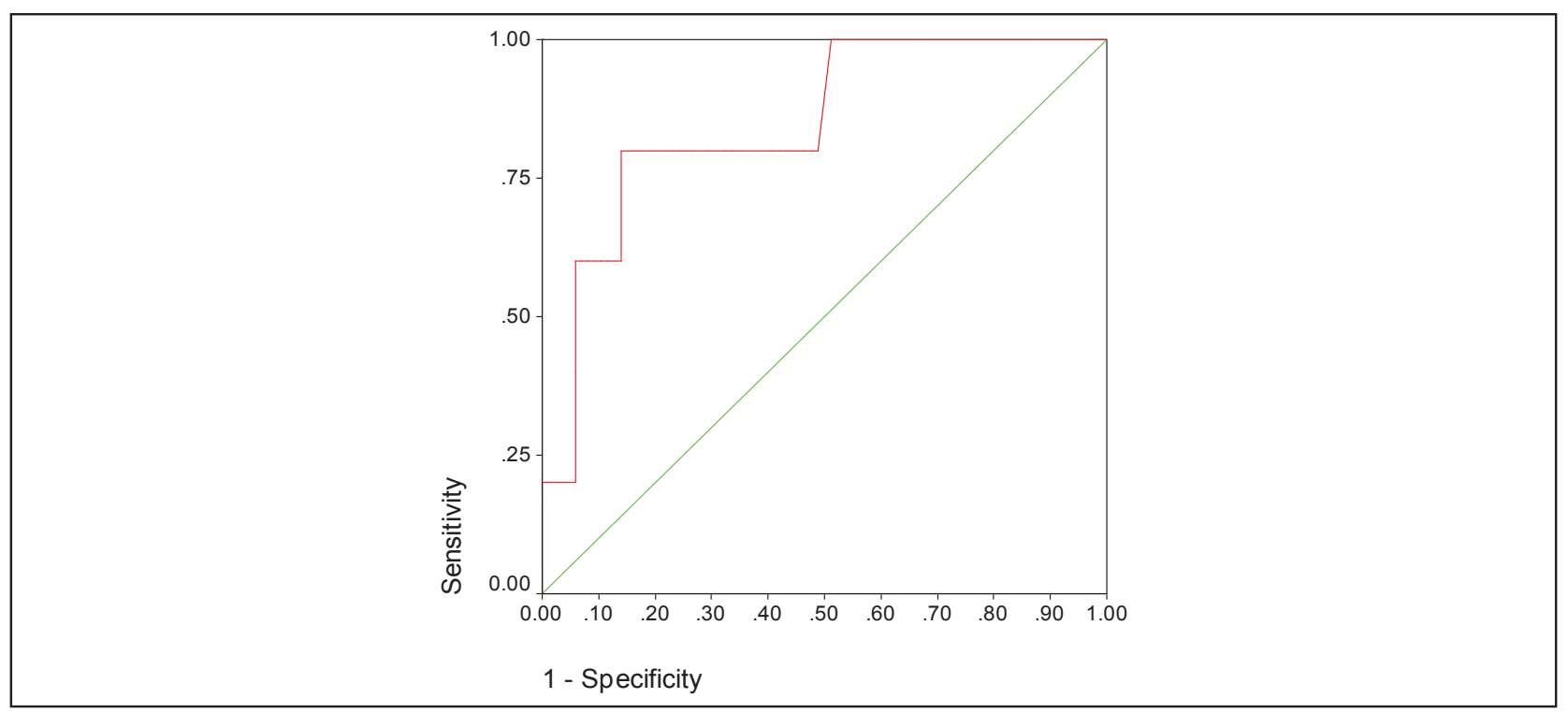

Fig 2: ROC analysis of fPSA measurement. The area under curve is 0.849 (95\% CI; 0.68-1.0, p=0.009)

\section{Discussion}

PSA is produced exclusively by the epithelial cells lining the prostatic acini and ducts of prostatic tissue. Because of its high specificity for prostate tissue, PSA is the preferred serum marker for $\mathrm{PCa}^{6}$. Unfortunately, PSA is specific for prostate tissue but not for prostate cancer. It is also found in abnormal concentrations in normal and benign changes of the prostate such as BPH and other non-neoplastic prostatic lesions. The usefulness of PSA as an early detector of prostate cancer by itself is questionable, owing to the overlap in PSA values seen in patients with $\mathrm{BPH}$ and in those with organ-confined prostate cancer ${ }^{7}$.
The clinically applicable reference values of tPSA is from 0 - $4.0 \mathrm{ng} / \mathrm{mL}$, but even within the "normal" range of PSA there is also the risk of cancer albeit at a smaller rate of $2 \%$. Intermediate values, i.e., value from 4.0-10.0 $\mathrm{ng} / \mathrm{mL}$ could be seen in patients with $\mathrm{BPH}$, prostatitis, $\mathrm{PIN}$ and $\mathrm{PCa}^{8-9}$. Serum fPSA level ranging from 0.4 to 1.3 is used as reference value in most laboratories. In this study, the fPSA level in patients of BPH ranged from $0.04-19.82 \mathrm{ng} / \mathrm{mL}$. BPH is a heterogenous disease that is characterized histologically by a variable degree of stromal and epithelial hyperplasia. Thus men with a predominance of epithelial hyperplasia 
are expected to have greater increases in PSA levels than men with predominant stromal hyperplasia. The variation in PSA levels in BPH can also be explained by the detection of various degrees of inflammatory changes detected histologically in TURP specimens. Twenty six (34.6\%) of our BPH patients had histological prostatitis. Kohner et al reported that $98.1 \%$ of $\mathrm{BPH}$ had histological prostatitis ${ }^{10}$. Blumfeld et al also reported that lymphocytic prostatitis was present in $95 \%$ of TURP specimens ${ }^{11}$. Many reports indicate that the serum PSA level is elevated in patients with clinical acute prostatitis ${ }^{12-15}$. The results of our study show that fPSA of patients with BPH without inflammation and patients with chronic inflammation ranged from normal level to $3.0 \mathrm{ng} / \mathrm{mL}$, while patients with active inflammation had values more than $3.0 \mathrm{ng} / \mathrm{mL}$. The mechanism through which histological inflammation within the prostate elevates serum PSA levels remains poorly understood. The epithelial cells surrounding the affected area may be stimulated to produce PSA through unknown substances released in association with the inflammatory processes ${ }^{16}$. On the other hand, Hasui et al suggested that the abnormal elevation of serum PSA levels is caused by leakage of PSA stored in the epithelial cells into the stromal tissue and blood circulating after epithelial cell death ${ }^{17}$.

In our study LGPIN was seen in $7.69 \%$ of the 91 patients. The fPSA levels in these patients were slightly elevated to levels less than $5.0 \mathrm{ng} / \mathrm{mL}$, while the levels were above $5.0 \mathrm{ng} / \mathrm{mL}$ in HGPIN. Some studies suggest that PIN causes serum PSA elevation ${ }^{18}$, while other studies dispute this relationship ${ }^{19,20}$. In our study most of the patients with prostatic carcinoma had serum fPSA levels more than $5.0 \mathrm{ng} / \mathrm{mL}$.

In this study though mean value of PPSA in PCa is statistically different than in the cases of BPH, fPSA in some cases of BPH is as high as $19.8 \mathrm{ng} / \mathrm{mL}$ and $\mathrm{fPSA}$ in one case of PCa is as low as $1.82 \mathrm{ng} / \mathrm{mL}$. Similar overlap has been witnessed in a number of studies using total PSA values, making selection of an optimum cut off value still controversial. One study has shown that clinical sensitivity of tPSA is $78 \%$ at a cut-off value of $4.0 \mathrm{ng} / \mathrm{mL}$. By lowering the cut-off value to $2.8 \mathrm{ng} /$ $\mathrm{mL}$, sensitivity increases to $92 \%$, whereas specificity decreases from $33 \%$ to $23 \%$. Raising the cut-off value to $8.0 \mathrm{ng} / \mathrm{mL}$ improves the specificity to $90 \%{ }^{21}$ In our data, though there is overlap of fPSA values between $\mathrm{BPH}$ and $\mathrm{PCa}$, yet it is statistically different. Clinical sensitivity of fPSA to distinguish PCa from BPH is $100 \%$ at cut-off value of $1.81 \mathrm{ng} / \mathrm{mL}$. However, at the cut-off value the specificity remains poor with only $49 \%$. By raising the cut-off value to $12.65 \mathrm{ng} / \mathrm{mL}$, specificity can improve to $94 \%$, limiting sensitivity to only $60 \%$ (Table 4). ROC analysis of our data suggest that use of cut-off value of $5.0 \mathrm{ng} / \mathrm{mL}$ will be optimum for clinical use to differentiate $\mathrm{PCa}$ with $\mathrm{BPH}$ as, sensitivity of $88.8 \%$ and specificity of $90.2 \%$ can be achieved.

There are limitations of this study. Patients with acute retention of urine (which may cause elevation in PSA levels) ${ }^{22}$ were not excluded from the study. Histologic correlation was done on TURP specimens and not prostatectomy specimens.

\section{Conclusion}

Serum fPSA is elevated marginally in patients with $\mathrm{BPH}$ without inflammation and patients with chronic inflammation. The higher grade lesions (HGPIN and $\mathrm{PCa}$ ) are associated with fPSA values more than $5 \mathrm{ng}$ / $\mathrm{ml}$. Since overlapping high values were also observed in acute prostatitis, we should tend to be more cautious about high-grade lesions that have not yet been diagnosed on TURP and a radical prostatectomy may have to be performed for evaluation.

\section{Acknowledgement}

The authors thank the staff of the Department of Pathology, Medicare National Hospital and Research Centre for their technical support. A special thanks to Gyanendra Sapkota for helping in data collection.

\section{Reference}

1. Wang MC, Valenzuela LA, Murphy GP, Chu TM. Purification of human prostate specific antigen. Invest Urol. 1979;17:159-63.

2. Stamey TA, Yang N, Hay AR, McNeal JE, Freiha FS, Redwine E. Prostate-specific antigen as a marker for adenocarcinoma of the prostate. N Engl J Med. 1987;317:909-16.

3. Catalona WJ, Smith DA, Ratliff TL, Dodda KM, Coplen DE, Yuan JJ, et al. Measurement of prostate-specific antigen in serum as a screening test for prostate cancer. $\mathrm{N}$ Engl J Med. 1991;324:1156-61.

4. Catalona WJ, Smith DS, Ratliff TL, Basler JW. Detection of organ- confined prostate cancer is increased through prostate-specific antigen based screening. JAMA. 1993;270:948-54.

5. Hudson MA, Bahnson RR, Catalona WJ. Clinical use of prostate specific antigen in patients with prostate cancer. J Urol. 1989;142:1011-7.

6. Osterling JE. Prostate-specific antigen: a critical assessment of the most useful tumor marker for adenocarcinoma of the prostate. J Urol. 1991;145:907-23.

7. Chan DW, Booth RA, Diamansid EP. Tumor marker. In, Brutis CA, Ashwood ER, Bruns DE, editors. Teitz textbook of clinical chemistry and 
molecular diagnostics. $4^{\text {th }}$ edition. New Delhi: Elsevier; 2006.p.2053-95.

8. Zivkovic S. Comparation of prostate specific antigen and density of prostate specific antigen in patients with benigh hyperplasia of prostate and prostate carcinoma, dissertation. Nis: Medical Faculty. 1998. p. 109-10.

9. Oesterling JE, Jacobsen JS, Klee GG, Pettersson K, Piironen T, Abrahamsson PA et al. Free, complexed and total serum prostate specific antigen: the establishment of appropriate reference range for their concentration and ratio. J Urol. 1995; 154:1090-5.

10. Kohnen PW, Drach GW. Pattern of inflammation in prostatic hyperplasia: a histologic and bacteriologic study. J Urol. 1979;121:755-60.

11. Blumenfeld W, Tucci S, Narayan P. Incidental lymphocytic prostatitis: selective involvement with nonmalignant glands. Am J Surg Pathol. 1992;16:975-81.

12. Morote-Robles J, Ruibal-Morell A, PalouRedorta J, de Torres-Mateos JA, Soler-Rosello A. Clinical behavior of prostatic specific antigen and prostatic acid phosphatase: A comparative study. Eur Urol.1988;14:360-6.

13. Seamond B, Whitaker B, Yang N, Shaw LM, Aderson K, Bollinger JR. Evaluation of prostatespecific antigen and prostatic acid phosphatase as prostatic cancer marker. Urology. 1986;28:4729.

14. Dalton DL. Elevated serum prostate-specific antigen due to acute bacterial prostatitis. Urology. 1989;33:465-70.

15. Neal DE, Clejan S, Sharma D, Moon TD. Prostate specific antigen and prostatitis: Effect of prostatitis on serum PSA in the human and nonhuman primate. Prostate. 1992;20:105-11.

16. Papsidero LD, Kuriyama M, Wang MC, Horoszewicz J, Leong SS, Valenzuela L, et al. Prostate antigen: a marker for human prostate epithelial cells. J Natl Cancer Inst. 1981;66:3742.

17. Hasui Y, Marutsuka K, Asada Y, Ide H, Nishi S, Osada Y. Relationship between serum prostate specific antigen and histological prostatitis in patients with benigh prostatic hyperplasia. Prostat.e 1994;25:91-6.

18. Brawer MK, Lange PH. Prostate-specific antigen and premalignant change: implication for early detection. CA Cancer J Clin. 1989;39:361-75.

19. Alexander EE, Qian J, Wollan PC, Myers RP, Bostwick DG. Prostatic intraepithelial neoplasia does not appear to raise serum prostate-specific antigen concentration. Urology. 1996;47:6938.

20. RonnettBM, Carmichael MJ, Carter HB, Epstein JI. Does high grade prostatic intraepithelial neoplasia result in elevated serum prostatespecific antigen levels? J Urol. 1993;150:3869.

21. Chan DW, Bruzek DJ, Oesterling JE, et al. Prostatic- specific antigen as a marker for prostatic cancer: A monoclonal and a polyclonal immunoassay compared. Clin Chem. 1987;33:1916-20.

22. Chawla R, Abraham R, Arora U, Mammen $\mathrm{K}$. Effect of urinary retention on the levels of prostate specific antigen(PSA) and prostatic acid phosphatase(PAP) in prostatic disease. Indian J Urol. 2003;19:120-4. 